\title{
ANALISIS KETERATURAN MATEMATIS PADA BUDAYA BANTEN
}

\author{
${ }^{1}$ Etika Khaerunnisa, ${ }^{2}$ Yani Setiani, ${ }^{3}$ Isna Rafianti \\ 1,2,3 Jurusan Pendidikan Matematika FKIP Universitas Sultan Ageng Tirtayasa, Jl.Raya Jakarta KM.4 Pakupatan \\ Serang Banten, Telp (0254) 280335 \\ etika_kh@untirta.ac.id
}

\begin{abstract}
Abstrak
Penelitian ini dilatarbelakangi oleh penelusuran informasi budaya banten yang ditinjau dari aspek matematika masih kurang menjadi fokus, padahal budaya mengandung unsur-unsur matematika di dalamnya, matematika adalah konstruksi dari budaya. Penelusuran keteraturan matematis pada budaya Banten dapat menjadi kajian yang dapat diintegrasikan dalam pembelajaran matematika pada materi transformasi. Metode penelitian yang digunakan dalam penelitian ini adalah penelitian kualitatif deskriptif. Berdasarkan hasil penelitian, pada objek gapura banten, masjid agung Banten, menara Banten, atap rumah adat Banten mengandung unsur refleksi, dilatasi, translasi, simetri, rotasi. Pada gapura Banten nampak keteraturan refleksi, dilatasi, translasi. Pada mesjid agung Banten nampak keteraturan rotasi, refleksi, dilatasi. Pada menara Banten terdapat keteraturan rotasi, dilatasi, refleksi. Pada atap rumah Banten memiliki keteraturan refleksi, dilatasi, rotasi. Dengan kajian terhadap budaya banten yang ditinjau dari konsep transformasi, dapat digunakan oleh guru dalam pembelajaran matematika pada materi transformasi di sekolah, sehingga diharapkan siswa bukan hanya mencapai kompetensi pengetahuan terkait materi transformasi, tetapi juga sebagai bentuk penguatan pendidikan karakter pada nilai nasionalis dengan memiliki kompetensi sikap kecintaan terhadap budayanya sendiri dapat tumbuh dan dimiliki oleh siswa sebagai jati diri bangsa.
\end{abstract}

Kata kunci: keteraturan matematis, budaya banten

\begin{abstract}
This research is motivated by the searching of banten cultural information which is viewed from mathematics aspect is still unfocus, whereas the culture contains the elements of mathematics, mathematics is the construction of the culture. The search for mathematical regularity in Banten culture can be a study that can be integrated in mathematics learning on transformation material. The research use descriptive qualitative research. Based on the results of research, on the object of Banten gate, Banten Great Mosque, Banten Tower, Banten traditional roof contains elements of reflection, dilatation, translation, symmetry, rotation. In Banten gate appears regularity of reflection, dilation, translation. At the grand mosque of Banten it appears the regularity of rotation, reflection, dilation. In the tower of Banten there is regularity of rotation, dilation, reflection. On the roof of the house Banten has the regularity of reflection, dilation, rotation. With the study of banten culture in terms of the concept of transformation, it can be used by teachers in learning mathematics on the transformation materials in schools, so that students are expected not only to achieve the knowledge competence related to transformation material, but also as a form of strengthening character education at nationalist value by having attitude competence love of its own culture can grow and be owned by students as national identity.
\end{abstract}

\section{Keywords: mathematical regularity, banten culture}

\section{PENDAHULUAN}

Budaya adalah sesuatu yang tidak bisa dihindari dalam kehidupan sehari-hari, karena budaya merupakan kesatuan utuh dan menyeluruh yang berlaku dalam suatu komunitas. Budaya atau kebudayaan diartikan sebagai hal-hal yang berkaitan dengan budi dan akal manusia. 
Kebudayaan dibagi menjadi dua bagian yaitu kebudayaan materi dan nonmateri. Kebudayaan nonmateri terdiri dari kata-kata yang dipergunakan orang, hasil penelitian, adat istiadat, keyakinan yang masyarakat anut dan kebiasaan yang masyarakat ikuti. Sedangkan kebudayaan materi merupakan benda-benda yang dapat dirubah dan dipakai orang (Horton, 1984). Menurut Hoenigman (Koentjaraningrat, 1982), wujud kebudayaan dibedakan menjadi tiga: 1) Gagasan (Wujud ideal) adalah kebudayaan yang berbentuk kumpulan ide-ide, gagasan, nilai-nilai, norma-norma, peraturan, dan sebagainya yang sifatnya abstrak; tidak dapat diraba atau disentuh, 2) Aktivitas (tindakan) adalah wujud kebudayaan sebagai suatu tindakan berpola dari manusia dalam masyarakat itu, 3) Artefak (karya). Artefak adalah wujud kebudayaan fisik yang berupa hasil dari aktivitas, perbuatan, dan karya semua manusia dalam masyarakat berupa benda-benda atau hal-hal yang dapat diraba, dilihat.

Banten merupakan daerah yang memiliki potensi budaya yang masih berkembang secara optimal. Keanekaragaman budaya Banten mencerminkan kepercayaan dan kebudayaan masyarakat setempat. Masyarakat dan kebudayaan Banten memiliki keunikan dan kekhasan tersendiri yang membedakan daerah satu dengan lainnya. Keunikan tersebut menjadikan sebuah modal bagi eksistensi budaya Banten untuk dapat diperkenalkan kepada masyarakat umum. Keunikan budaya Banten dapat dilihat dari bentuk kebudayaan yang bersifat nonmateri yaitu berbagai macam kesenian tradisional, upacara adat, tradisi kepercayaan dalam ritual keagamaan. Kegiatan budaya ini masih dipertahankan dan dilestarikan karena masyarakat Banten beranggapan bahwa dalam suatu budaya itu mengandung nilai-nilai budaya yang telah mengakar dalam jiwa masyarakat Banten. Selain kebudayaan yang bersifat nonmateri, Banten dikenal memiliki kebudayaan yang bersifat materi yang beragam. Berbagai sumber daya budaya yang cukup menarik berhasil ditemukan di wilayah ini yang ditandai oleh temuan-temuan, dan yang paling dominan dan sangat kaya adalah tinggalan monumental dalam bentuk bagunan bangunan megah pada masa Islam Awal dari Kesultanan Banten. Peninggalan ini merupakan suatu budaya dan peradaban yang tinggi yang telah diwariskan nenek moyang.

Masa lalu Banten dikenal karena di daerah ini pernah berdiri sebuah kerajaan Islam. Kebudayaan Banten semakin berkembang setelah bersentuhan dengan kebudayaan luar. Pengaruh budaya dari luar tersebut datang dari India yang membawa pengaruh agama Hindu dan Budha, masuknya pengaruh India juga berdampak pada sistem sosial dan pemerintahan yang ditandai dengan berdirinya kerajaan, salah satu kerajaan Hindu yang pernah ada di Banten ialah kerajaan Banten Girang (abad ke 10 sampai abad ke 16). Masuknya pengaruh Islam kemudian berdampak pada mundurnya pengaruh Hindu-Buda di Banten. Kerajaan Banten Girang berada di bawah penguasa Islam yang kemudian mendirikan kerajaan di sekitar Teluk Banten. Pusat kotanya dikenal dengan nama Surosowan, yang kini disebut Banten lama, kerajaan Islam di Banten ada dari abad ke 16 sampai abad ke 19 (Juliadi, dkk: 2005). Kerajaan Islam Banten mengalami kemuduran setelah masuknya pengaruh VOC 
(Vereniging Oost Indie Compagnie) yaitu perkumpulkan dagang Belanda di Indonesia tahun 16021799. Belanda selanjutnya menghancurkan pusat kota kesulthanan dan memindahkan pusat pemerintahan ke Serang. Belanda berakhir setelah mengalami kekalahan oleh Jepang tahun 1942 (Juliadi, dkk : 2005).

Kini masa lalu kesulthanan Banten tersebut hanya menyisakan bukti-buktinya, Bukti penginggalan tersebut antara lain berupa berkas kompleks keraton Surosowan yang dibangun pada masa pemerintahan Maulana Hasanudin, Mesjid Agung Banten, Komplek keraton Kaibon, makam raja-raja Banten dan keluarganya, mesjid pecinan tinggi, mesjid koja, benteng SpeelWijk, Kelenteng Cina, Watu Gilang, Danau Tasikardi, Mesjid dan makam Sultan Kenari, dan lainnya. Benda-benda peninggalan tersebut termasuk ke dalam kategori kebudayaan yang berupa artefak (karya) yang didalamnya terkandung konsep-konsep matematika.

Benda-benda seperti mesjid agung banten, keraton kaibon, gapura kaibon, menara banten merupakan bentuk geometri yang memiliki sifat-sifat keteraturan matematis diantaranya translasi (pergeseran), refleksi (pencerminan), rotasi (perputaran), dilatasi (penskalaan). Translasi merupakan perubahan objek dengan cara menggeser objek dari satu posisi ke posisi lainnya dengan jarak tertentu. Rotasi adalah perputaran yang di tentukan oleh pusat dan besar sudut putar. Refleksi (pencerminan) adalah suatu transformasi yang memindahkan tiap titik pada bidang dengan menggunakan sifat bayangan cermin dari titik-titik yang dipindahkan. Dilatasi adalah suatu transformasi yang mengubah ukuran (memperbesar dan memperkecil) suatu bangun tetapi tidak mengubah bentuk bangunnya.

Pengetahuan mengenai transformasi geometri sangat berguna bagi seseorang terlebih siswa dalam rangka membangun kemampuan spasial, kemampuan penalaran geometri, dan memperkuat pembuktian matematika (Edward, 1997: 187). Kemampuan-kemampuan itu (Patterson, 1973: 90) dapat membuat siswa mengeksplorasi konsep matematika abstrak tentang konsep kongruen, simetri, kesebangunan, dan garis paralel; memperkaya pengalaman, pemikiran dan imaginasi geometri siswa; serta meningkatkan kemampuan spasial siswa. Untuk menanamkan kemampuan tersebut, maka perlu sekiranya mengenalkan konsep transformasi dengan mengintegrasikan budaya Banten. Dengan demikian rumusan masalah yang diteliti adalah Bagaimana keteraturan matematis pada budaya Banten?. Adapun tujuan penelitian ini adalah untuk mengetahui ketarturan matematis pada budaya Banten, yang kajiannya dapat digunakan oleh guru dalam pembelajaran matematika pada materi transformasi di sekolah, sehingga diharapkan siswa bukan hanya mencapai kompetensi pengetahuan terkait materi transformasi, tetapi juga kompetensi sikap kecintaan terhadap budayanya sendiri dapat tumbuh dan dimiliki oleh siswa sebagai jati diri bangsa.

Prima, Vol. 2, No. 2, Juli 2018, 81-91 


\section{METODE PENELITIAN}

Penelitian ini tergolong penelitian kualitatif deskriptif. Moleong (2006) menyebutkan penelitian kualitatif digunakan untuk meneliti masalah yang membutuhkan studi yang medalam seperti studi perilaku, motivasi, persepsi, dampak, dan lainnya secara holistik dan dengan cara deskripsi dalam bentuk kata-kata dan bahasa dalam konteks khusus yang alamiah. Obyek penelitian adalah keteraturan matematis dari peninggalan budaya Banten yaitu mesjid agung banten, keraton kaibon, gapura kaibon, menara banten. Prosedur Analisis, pertama mengidentifikasi masalah, merumuskan masalah, melakukan observasi ke lokasi, melakukan wawancara sekitar lokasi, mengambil dokumentasi di lokasi, melakukan kajian literatur, dan mengambil kesimpulan.

\section{HASIL PENELITIAN DAN PEMBAHASAN}

\section{Gapura Kaibon}

Gapura khas Banten adalah gapura kaibon. Kaibon berasal dari kata ka-ibu-an, tempat tinggal yang diperuntukkan bagi ibunda Sultan. Terletak sekitar 500 meter sebelah tenggara Keraton Surosowan. Pada tahun 1832, bangunan keraton kaibon dihancurkan oleh Belanda, saat ini yang tersisa hanya bagian pondasinya, runtuhan dinding dan sisi kiri dari bagian pintu masuknya.

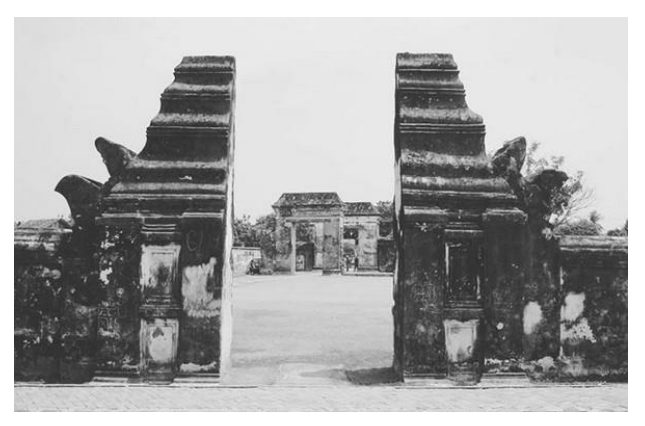

Gambar 1. Gapura Kaibon

Gambar di atas merupakan bentuk dasar dari gapura Kaibon. Konstruksi bangunannya cukup sederhana, yaitu dengan material batu bata yang ditumpuk, dilapisi dengan pasir beserta semen, gapura khas Banten ini dibangun. Berdasarkan kedalaman letaknya, pembangunan gapura ini menggunakan pondasi dangkal dengan jenis pondasi menerus. Pondasi menerus dipasang di bawah seluruh panjang dinding gapura dengan lebar dasar

Sama besar dan terletak pada kedalaman sama. Untuk menuju keraton terdapat 4 buah pintu bentar. Yang tersisa kini hanya bagian mihrabnya saja. Untuk memasuki masjid harus melalui pintu paduraksa (Dinas Budaya dan Pariwisata Provinsi Banten, 2011). 


\section{Masjid Agung Banten}

Masjid Agung Banten berdiri di sebelah Barat Alun-Alun. Masjid ini mempunyai keistimewaan pada bagian pawestren yang merupakan bangunan khusus untuk wanita yang diperkirakan di buat pada masa pemerintahan Maulana Muhammad (1580-1586). Keistimewaan lain masjid ini adalah bagian serambi yang terdapat di keempat sisi dan ruang utama yaitu: 1). Serambi Selatan: dijadikan sebagai tempat pemakaman yang memuat 15 makam dengan letak yang tidak beraturan; 2). Serambi timur: tempat yang terluas dan mempunyai atap yang terpisah dengan bangunan utama serta dibangun pada masa pemerintahan Maulana Yusuf (1570 - 1580); 3). Serambi Utara dan Selatan berada di bawah naungan atap bangunan utama. Atap masjid bertingkat lima sebagaimana atap-atap masjid kerajaan seperti yang ditemukan di Jepara dan Ternate (Astiti, 2016).

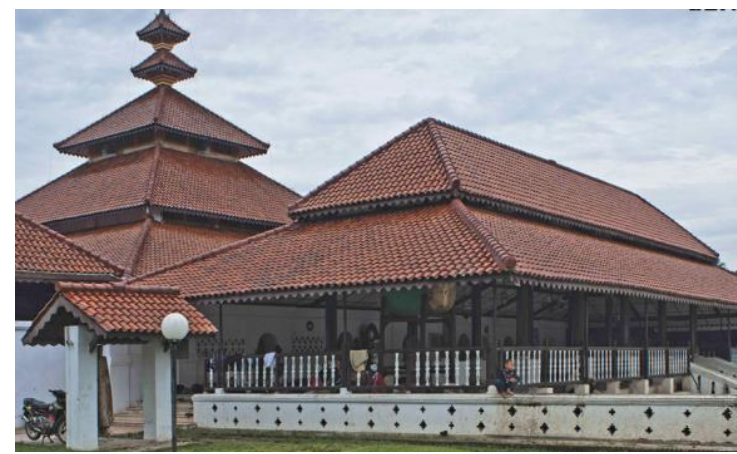

Gambar 2. Mesjid Agung Banten

Keteraturan yang nampak pada mesjjid agung Banten yaitu:1) Simetri. Simetri yang dikenal dengan bentuk yang mempunyai titik sumbu, yang kemudian dapat membagi dua bagian yang sama besar. Jika dilihat pada bentuk atap masjid, yang berbentuk limas segi empat dan sisi dari bentuknya adalah berbentuk segitiga sama kaki. Bentuk segitiga sama kaki adalah bentuk yang simetri karena mempunyai titik sumbu dan jika dibagi menjadi dua bagian yang sama, maka mempunyai ukuran yang sama besar pula. Begitu juga pada bentuk bangunnya, sama karena tersusun dari bangun yang mempunyai sisi segitiga sama kaki tersebut. Inilah yang disebut keteraturan ukuran dan pola simetri pada mesjid agung Banten, 2) Rotasi. Rotasi yang dikenal adalah perputaran. Jika diperhatikan pada atap masjid, kita dapat mengetahui adanya perputaran pada bentuk atap masjid, yaitu jika diputar ke kanan ataupun kekiri, bentuknya akan tetap sama. Inilah yang disebut keteraturan ukuran dan pola rotasi, yang dapat dilihat pada atap masjid, 3) Refleksi. Refleksi yang dikenal adalah pencerminan. Jika diperhatikan pada atap masjid, dapat dilihat adanya pencerminan pada atapnya, yaitu bentuk atap yang paling atas sampai yang paling bawah, jika dicerminkan mempunyai bentuk yang

Prima, Vol. 2, No. 2, Juli 2018, 81-91 
sama. Inilah yang disebut keteraturan ukuran dan pola refleksi yang dapat dilihat pada bagian atap masjid, 4) Dilatasi. Dilatasi yang dikenal adalah perbesaran. Jika diteliti secara dilatasi pada bangunan bagian atap masjid agung Banten yang terlihat seperti pagoda cina. Atap masjid berbentuk seperti bangun ruang limas segi empat yang jika di lihat dari atas ukurannya semakin kebawah semakin membesar, dan bantuknya tetap sama. Pada atap masjid inilah terdapat keteraturan ukuran dan pola dilatasi

\section{Menara Banten}

Menara ini terletak di halaman sisi Timur Masjid Agung atau sekitar 10 meter dari pagar tembok kolam. Menara dibangun dengan kontruksi tembok dengan tinggi puncak 23,155 meter dari permukaan tanah, dengan bagian dasar dan tubuh berdenah segidelapan. Pintu masuk pada bagian atas merupakan bidang lengkung dan ditengahnya terdapat panel segi empat serta berada di sisi utara bagian tubuh. Pada langit -langit bidang lengkung terdapat ornament mirip kepala peluru. Ornamen ini merupakan bentuk hiasan kala yang distilir dan dianalogikan dengan pintu masuk ke candi-candi masa Hindu -Budha. Bagian puncak merupakan kepala menara yang terdiri dari dua tingkat yaitu: tingkat Pertama merupakan kubah yang bagian atasnya terpenggal, dan tingkat Kedua adalah kubah yang lebih kecil. Pada bagian puncak terdapat memolo atau mustoko berwarna merah hati yang terbuat dari tanah liat bakar menyerupai bunga yang sedang mekar dan wisatawan dapat melalui lorong tangga dengan kontruksi melingkar (Dinas Budaya dan Pariwisata Provinsi Banten, 2011)

Analisis keteraturan menara banten dapat dilihat pada tabel berikut.

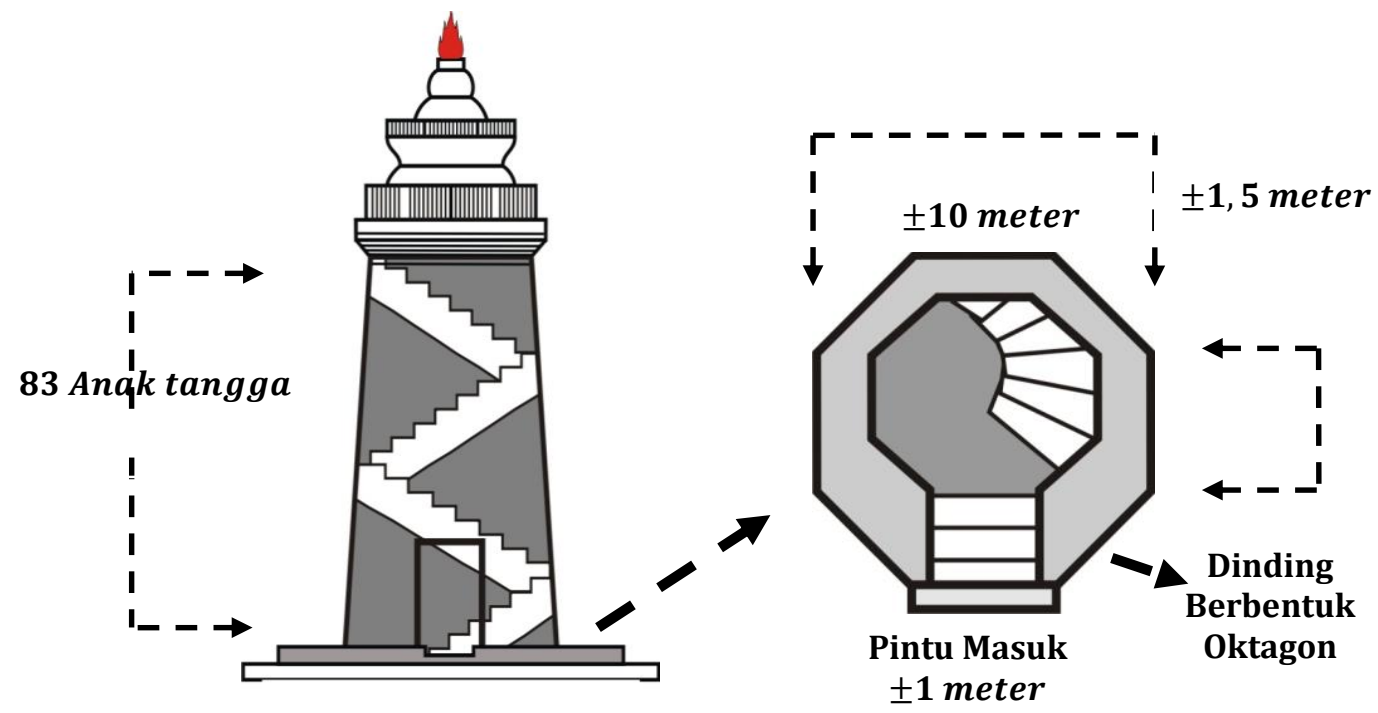

Gambar 3. Menara Agung Banten 
Tabel 1. Keteraturan Menara Banten

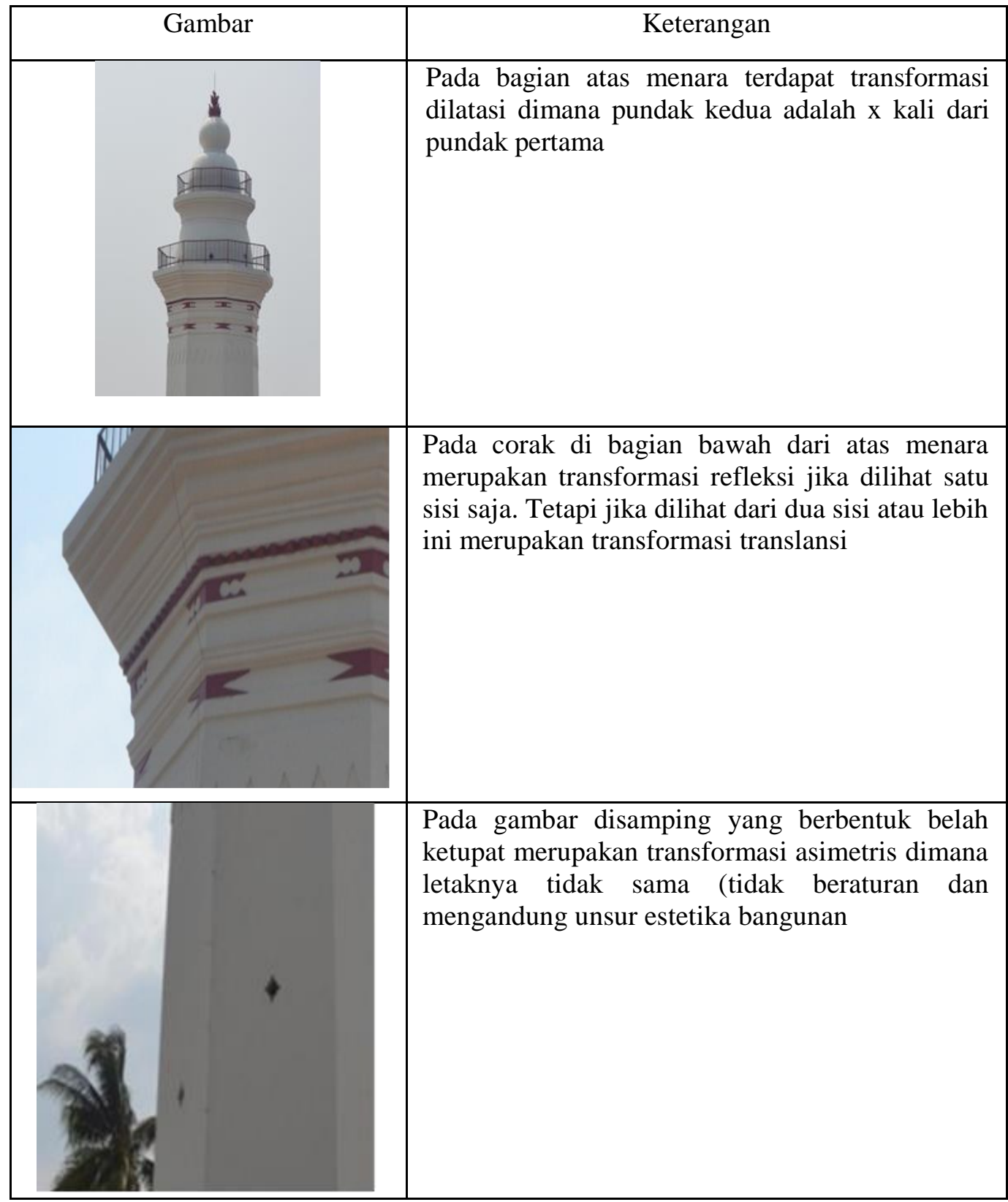

Prima, Vol. 2, No. 2, Juli 2018, 81-91 


\begin{tabular}{|l|l|}
\hline & $\begin{array}{l}\text { dari gambar di samping yang berbentuk persegi } \\
\text { panjang merupakan transformasi simetris yaitu } \\
\text { pola persegi panjang yang didapat }\end{array}$ \\
\hline & $\begin{array}{l}\text { Dari dua gambar di samping menunjukkan bahwa } \\
\text { setiap sisi dari menara merupakan perputaran sisi } \\
\text { pada sumbu vertikal dan membentuk bangun } \\
\text { ruang. Hal ini membuktikan bahwa menara } \\
\text { memiliki transformasi rotasi. }\end{array}$ \\
\hline
\end{tabular}

\section{Keraton Kaibon}

Kaibon berasal dari kata ka-ibu-an, yaitu tempat tingggal yang diperuntukkan bagi ibunda Sultan. Keraton Kaibon merupakan bekas kediaman Sultan Syaffiudin, seorang sultan Banten yang memerintah tahun 1809-1815. Sultan wafat dan kedudukannya digantikan oleh putranya yang berusia 5 tahun. Untuk sementara pemerintahan dipegang oleh ibunya yaitu Ratu Aisyah. Tahun 1832, keraton 
kaibon dihancurkan oleh Belanda, dan hanya tersisa bagian fondasinya, runtuhan dinding dan sisi kiri di bangian pintu masuknya (Juliadi, 2005). Analisis keteraturan pada keraton surosowan dapat dilihat pada tabel berikut.

Tabel 2. Keteraturan Keraton Surosowan

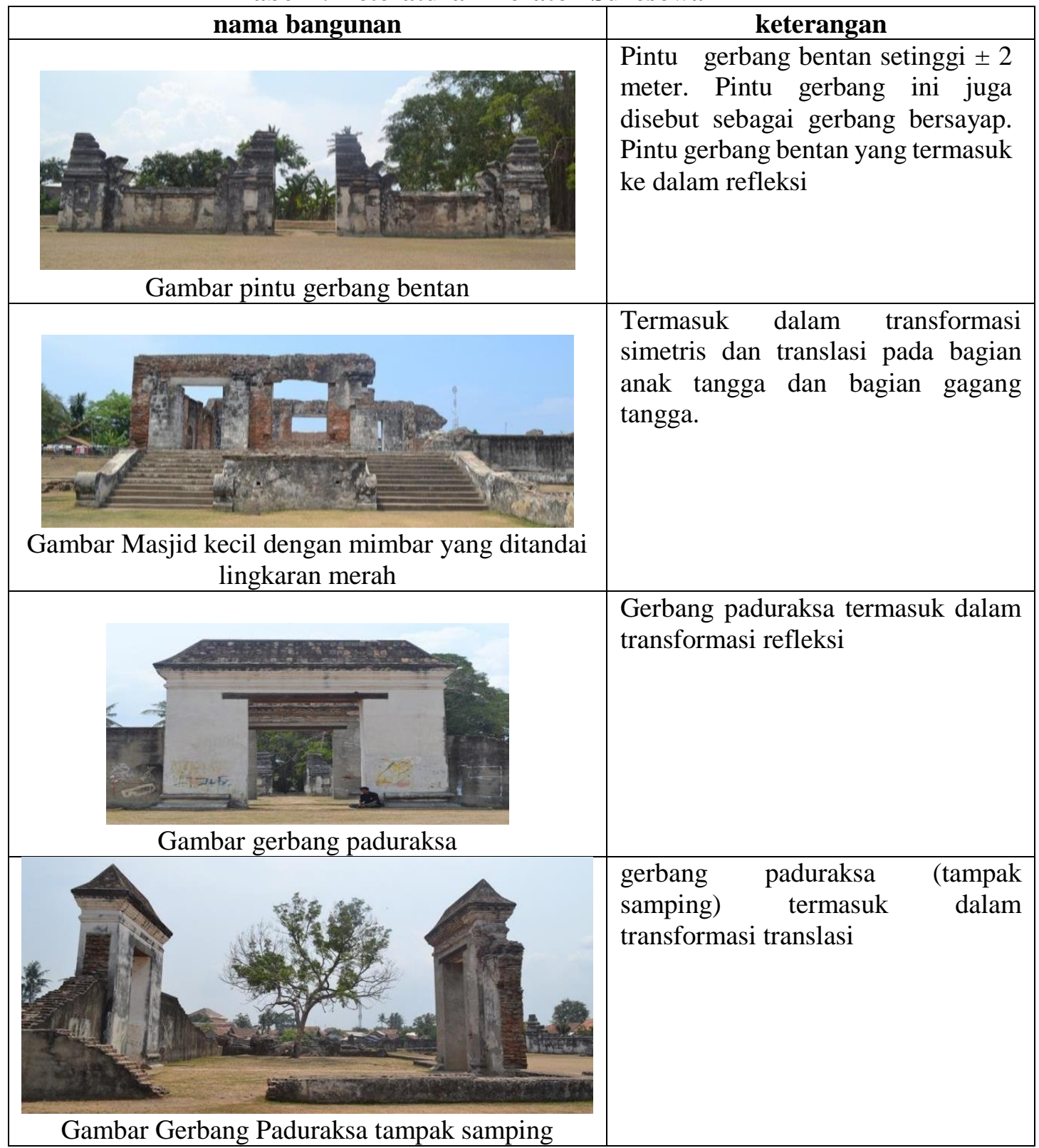

Prima, Vol. 2, No. 2, Juli 2018, 81-91 


\section{Atap Rumah Khas Banten}

Secara umum rumah adat Baduy merupakan rumah panggung yang hampir secara keseluruhan rumah menggunakan bahan bambu. Rumah adat baduy ini sendiri terkenal dengan kesederhanaan, dan dibangun berdasarkan naluri manusia yang ingin mendapatkan perlindungan dan kenyamanan. Atap rumah adat baduy terbuat dari daun yang disebut sulah nyanda. Bilik rumah dan pintu rumah terbuat dari anyaman bambu yang dianyam secara vertikal. Teknik anyaman tersebut dikenal dengan nama sarigsig tersebut dibuat hanya dengan berdasarkan perkiraan, tidak diukur terlebih dahulu. Kunci rumah dibuat dengan memalangkan dua buah kayu yang ditarik atau didorong dari bagian luar rumah. Ada tiga ruangan dalam bangunan rumah adat ini, yaitu ruangan yang dikhususkan untuk ruang tidur kepala keluarga juga dapur yang disebut imah (CIF, 2010).

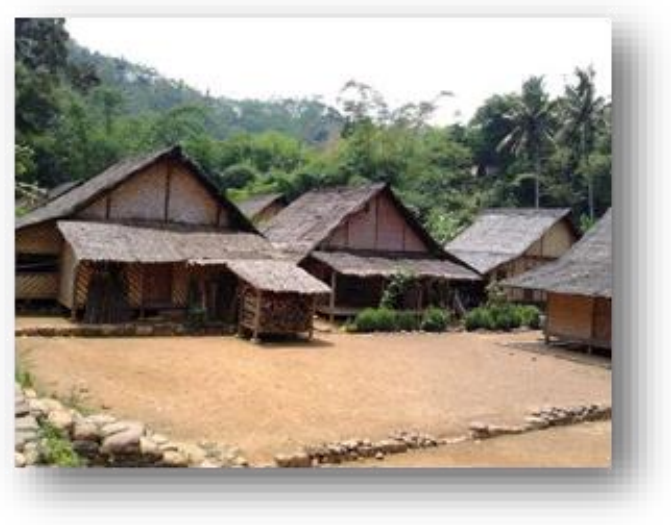

\section{Gambar 4.Atap Rumah Khas Banten}

Keteraturan yang nampak pada atap rumah Banten yaitu: 1) Simetri. Terdapat garis yang membagi atap rumah adat Banten di tengah- tengah, dengan acuan titik di ujung atap, maka akan membagi bidang yang sama besar, 2) Refleksi. Jika gambar atap rumah adat Banten tersebut direfleksi terhadap sumbu y maka akan menghasilkan pencerminan yang sama seperti gambar pada awalnya. Jika direfleksi terhadap sumbu x maka akan menghasilkan pencerminan yang terbalik dari gambar awalnya, 3) Rotasi. Saat atap rumah adat Banten dilihat dari depan seperti berbentuk segitiga dengan di kedua sisinya terdapat nyanda, maka ketika atap rumah tersebut diputar 90 derajat kekanan ataun kekiri, maka atap rumah tersebut akan tampak samping yang berbentuk trapesium dengan terdapat nyanda didepan dan dibelakangnya, 4) Dilatasi. Jika atap rumah adat Banten tersebut diperbesar maka akan tampak sama seperti aslinya (tidak ada perubahan) 


\section{SIMPULAN DAN SARAN}

Pada gapura Banten nampak keteraturan refleksi, dilatasi, translasi. Pada mesjid agung Banten nampak keteraturan rotasi, refleksi, dilatasi. Pada menara Banten terdapat keteraturan rotasi, dilatasi, refleksi. Pada atap rumah Banten memiliki keteraturan refleksi, dilatasi, rotasi.

Dengan kajian terhadap budaya banten yang ditinjau dari konsep transformasi, dapat digunakan oleh guru dalam pembelajaran matematika pada materi transformasi di sekolah, sehingga diharapkan siswa bukan hanya mencapai kompetensi pengetahuan terkait materi transformasi, tetapi juga sebagai bentuk penguatan pendidikan karakter pada nilai nasionalis dengan memiliki kompetensi sikap kecintaan terhadap budayanya sendiri dapat tumbuh dan dimiliki oleh siswa sebagai jati diri bangsa

\section{DAFTAR PUSTAKA}

IF, Redaksi. (2010). Atlas Bergambar Seni Budaya Indonesia. Surabaya: Cakrawala.

Dinas Budaya dan Pariwisata Provinsi Banten. (2011). Dokumentasi Benda Cagar Budaya dan Kepurbakalan Provinsi Banten. Serang: Dinas Budaya dan Pariwisata Provinsi Banten.

Edwards, LD.1997. "Explore Ring the Terrority before Proof: Students' Generalization in a computer Microworld for Transformation Geometry". International Journal of Computers for Mathematical Learning. Vol 1. Hal.187-215.

Horton,P.B. (1984). Sosiologi jilid I. Jakarta: Erlangga.

Juliadi,dkk. (2005). Ragam Pusaka Budaya Banten. Serang: Balai Pelestarian Peninggala Purbakal Serang.

Koentjaraningrat. (1982). Pengantar Antropologi. Jakarta: Aksara Baru.

Moleong, Lexy. (2006). Metodologi Penelitian Kualitatif. Bandung: PT Remaja Rosdakarya.

Paterson, J. C. (1973). "Informal Geometry in Grades 7-14". In K.B. Henderson (Ed.), Geometry in the Mathematics Curriculum: Thirty-Sixth Yearbook. (pp. 52-91). Washington, DC: NCTM.

Astiti, Ayu, N.K. (2016). Pengelolaan Kawasan Situs Kota Kuno Banten Sebagai Destinasi Wisata Budaya Untuk Meningkatkan Pergerakan Wisatawan Nusantara. Jurnal Destinasi Kepariwisataan Indonesia. Vol. 1 No. 1 Juni 2016.hal 1-26.

Prima, Vol. 2, No. 2, Juli 2018, 81-91 